\title{
Effect of resistance training exercise combined with high protein diet on body weight and muscle mass in underweight adolescent males
}

\author{
Wittawas Sajjapong ${ }^{1 *}$, Preeya Leelahagul ${ }^{1}$, Sitha Pongphibool² \& Narupon \\ Thongsuk $^{3}$ \\ ${ }^{1}$ Program in Nutrition, Faculty of Medicine Ramathibodi Hospital and Institute of \\ Nutrition, Mahidol University, Bangkok, Thailand, ${ }^{2}$ Program in Sports and Exercise \\ Science, Faculty of Sport Science, Chulalongkorn University, Bangkok, Thailand, \\ ${ }^{3}$ Princess Chulabhorn Science High School Chiang Rai, Chiang Rai, Thailand
}

\begin{abstract}
Introduction: Many underweight males take commercial protein supplements to increase their body weight and build muscle. Nonetheless, commercial protein supplements may cause adverse effects. This study aimed to determine the effects of resistance training exercise combined with a high protein diet on body weight and muscle mass in underweight adolescent males. Methods: A repeated measures design study was conducted on nine males aged 12-15 years with low body weight. Energy and protein requirements were calculated, and energy and protein consumptions were measured for each meal during the high protein diet without exercise (HP) period and the high protein diet with resistance exercise (HPE) period. Subjects engaged in three resistance training sessions each week during HP-E period, for eight weeks. Dietary intake, body composition, blood biochemistry, physical fitness, and self-esteem were assessed. Results: In HP-E period, resistance training exercise combined with a high protein intake $(2.14 \mathrm{~g} / \mathrm{kg} / \mathrm{d})$ increased body weight and lean tissue mass (LTM) by $0.5 \mathrm{~kg}$ and $0.5 \mathrm{~kg}$, respectively. Resistance training during HP-E period increased arm, leg, and trunk muscle strength by $20.2 \%, 7.2 \%$, and $14.5 \%$, respectively, more than high protein diet alone during HP period. High protein intake in HP-E period did not affect blood urea nitrogen (BUN) and creatinine levels $(11.0 \mathrm{mg} / \mathrm{dL}$ and $0.70 \mathrm{mg} / \mathrm{dL}$, respectively). Conclusion: Eight weeks of resistance training combined with a high protein diet increased body weight and LTM without adverse effects. In particular, resistance exercise predominantly increased muscle strength. Kidney function was not affected by high protein consumption throughout this study.
\end{abstract}

Keywords: High protein diet, resistance exercise, adolescent male, body weight, muscle strength

\section{INTRODUCTION}

Underweight in adolescents is one of the most common problems in many Asian countries. A previous study indicated that the prevalence of underweight among 16.5-17.5 years old Japanese adolescents of both sexes in 2001 was marginally increased compared with that

\footnotetext{
*Corresponding author: Wittawas Sajjapong

Program in Nutrition, Faculty of Medicine and Institute of Nutrition, Ramathibodi Hospital, Mahidol University, Rama VI Road, Ratchathewi, Bangkok 10400, Thailand

E-mail: wsajjapong@hotmail.com

doi: https://doi.org/10.31246/mjn-2020-0039
} 
in 1978-1981 (Inokuchi et al., 2007). Among adolescents in Ho Chi Minh City, Vietnam, $13.1 \%$ were reported to be underweight (Tang et al., 2007). The weight status of Thai adolescents was investigated and published in 2013 as part of the "Waisai-Health Program", which conducted a survey of the weight status of adolescent Thai students at Srinagarindra the Princess Mother School, Phayao (SW.PY.) Among 313 male and 376 female students who participated in this programme, $5.8 \%$ of males and $5.4 \%$ of females were underweight (Suttikomin et al., 2018).

Sufficient protein consumption can increase body weight and muscle mass. So far, food protein quality, as assessed by digestibility, net protein utilisation, and biological value, has been better for animal-based protein sources such as meat, eggs, milk, and its constituents than for plant-based protein sources such as raw cereals and legumes (Berrazaga et al., 2018). The protein digestibility corrected amino acid score (PDCAAS) is a composite indicator of protein quality used to assess the ability of dietary protein to meet the body's amino acid requirements. A given dietary protein cannot fully meet the body's essential amino acid requirements when its PDCAAS is less than $100 \%$. Apart from some soy protein isolates, plant-based protein sources that have been tested to date are characterised by PDCAASs that are less than $100 \%$ and therefore, lower than those of animal proteins (Berrazaga et al., 2018). Likewise, consumption of soy protein has resulted in a lower synthetic rate of muscle protein when compared to consumption of animal protein such as whey, milk, or beef (Vliet, Burd \& Loon, 2015).

Alternatively, resistance training exercise can also lead to an increase in body weight and muscle mass. This is an effective strategy not only for increasing muscle mass and body weight, but also for improving strength and endurance, which consequently promotes overall health. Importantly, the role of amino acid availability in regulating muscle protein synthesis (MPS) in response to amino acids, protein ingestion, and exercise has been reported. It has been shown that the quantity of protein intake is significantly correlated with an increase in body weight and muscle mass. Additionally, a correlation between aerobic fitness and body weight has been documented (Bray et al., 2012). A study on the effects of a ten-week resistance or aerobic exercise training on body weight and lean body mass demonstrated that body weight and lean body mass of persons in the resistance training group were slightly increased, while total body fat mass was significantly decreased when compared to the control group (Donges, Duffield \& Drinkwater, 2010).

Data from the "Waisai-Health Program" indicated that adolescent males tend to have more underweight problems than adolescent females (Suttikomin et al., 2018). The pilot study of this research found that all male students wanted to improve their body weight status, which can result in a healthier body and mind. However, many of them regularly took commercial whey protein to increase their body weight and build muscle, even though the purity and safety of whey proteins are not guaranteed. Therefore, this study aimed to optimise the levels of protein intake from natural sources such as meat, fish, eggs, and dairy products, and incorporate a resistance exercise programme for underweight adolescent males to improve their body weight and muscle mass.

\section{MATERIALS AND METHODS}

\section{Study design and subjects}

This repeated measures design study was conducted among underweight male 
students at the Princess Chulabhorn Science High School Chiang Rai (PCSHSCR), which is a boarding school, based on pre-specified inclusion and exclusion criteria. The inclusion criteria were underweight and underfat males aged between 12 and 15 years with a body mass index (BMI)-for-age below the $<5^{\text {th }}$ percentile (De Onis, Onyango \& Borghi, 2007) and body fat-for-age below the $2^{\text {nd }}$ percentile (McCarthy et al., 2006). The exclusion criteria were those with chronic diseases, e.g. liver disease, kidney disease, heart disease, thyroid disease, thalassaemia, and the presence of injuries in the past six months before intervention. Out of 34 volunteers, only nine adolescents met the inclusion criteria for BMI and body fat percentage. Therefore, only nine low body weight and low body fat adolescent males were selected for this study. According to a priori calculation, nine participants in each intervention period were sufficient to generate a power of 0.8 at an alpha level of 0.05 for dependent measures, based on previous studies (Hammami et al., 2016). This study was divided into three periods, with eight weeks for each period: baseline (BL) period, high protein diet without exercise (HP) period, and high protein diet with resistance exercise (HP-E) period.

\section{Dietary intake}

All subjects maintained their usual dietary intake during the BL period; they were allowed to eat ad libitum and 24-hour dietary intake was recorded everyday by themselves throughout the study period.

In the HP and HP-E periods, in order to increase the body weight of underweight males to normal body weights and provide adequate energy for their energy expenditures, their total energy requirements were derived from the Harris-Benedict equation $\times$ activity factor (1.200 in HP for sedentary living and 1.375 in HP-E for moderate activity). Hence, the amount of protein intake was $1.6-1.7 \mathrm{~g} / \mathrm{kg} / \mathrm{d}$, as recommended by the International Olympic Committee (IOC). The use of 24-hour dietary records were monitored by the researchers throughout the HP and HP-E periods. The energy and protein content of each meal was calculated and subsequent meals were prepared by the school cafeteria for the subjects, under the supervision of the researchers. Compliance of subjects with the daily prescribed food intake was $100 \%$.

Basal metabolic rate (BMR) was estimated so that underreporting of energy intake (EI) could be evaluated. A cut-off value of 0.9 was used to define underreporting of EI in terms of EI:BMR ratio (Kye et al., 2014). When EI:BMR was $<0.9$, subjects were classified as under-reporters. Only one subject in the BL period was an under-reporter.

\section{Exercise}

In the HP-E period, subjects engaged in three resistance training sessions each week with upper body (push-ups, dips, bridges, and planks) and lower body (squats and lunges) exercises on Monday, Wednesday, and Friday at school. Each exercise session lasted approximately 4560 minutes (excluding ten-minute warmup and cool-down periods). All sessions were supervised by the researchers. The format and relative intensity of the training protocols for push-ups, dips, squats, and lunges composed of two sets of eight repetitions in week one, three sets of eight repetitions in weeks 2-3, and three sets of 12 repetitions in weeks 4-8. The format and relative intensity of the training protocols for bridge and plank exercises involved maintaining the correct position for the maximum possible time. 


\section{Body composition assessment}

Body composition was assessed weekly on early Monday morning before breakfast. Height was measured by using a calibrated stadiometer (Seca model 216, USA). Body weight (kg), body fat ( $\%$ of body weight), fat mass $(\mathrm{kg})$, fat-free mass (FFM, kg), predicted muscle mass or bone-free lean tissue mass (LTM, kg), and total body water (\%) were assessed using a Tanita BC418MA segmental body composition analyser (Tanita Co. Ltd., Japan). Hand grips were used to allow the BC418 model to assess segmental body composition. Muscle circumferences, including those for the abdomen, arm, buttock, calf, forearm, hip, mid-thigh, and waist circumferences were assessed according to the American College of Sports Medicine (ACSM) guidelines for exercise testing and prescription.

\section{Biochemical assessment}

Biochemical measurements were conducted at the BL, HP, and HP-E periods and included measurements of haemoglobin, fasting blood sugar (FBS), total cholesterol (TC), high density lipoprotein cholesterol (HDL-C), low density lipoprotein cholesterol (LDL-C), triglyceride, serum uric acid, blood urea nitrogen (BUN), and creatinine. These parameters were analysed using an automated blood BS-400 Chemistry Analyzer (Mindray Bio-Medical Electronics Co., Ltd. Shenzhen, China).

\section{Dietary assessment}

Energy and nutrient intakes were recorded for 24 hours, and dietary intake was calculated using the INMUCALNutrients version 3 software provided by the Institute of Nutrition, Mahidol University. Estimated branch chain amino acid (BCAA) intake was calculated based on the amino acid content in foods according to the USDA National Nutrient Database for Standard Reference: USDA
ARS (Agricultural Research Service, U.S. Department of Agriculture) (Table 1).

\section{Strength tests}

There were three procedures for the strength tests: muscle power was measured using a broad jump, and muscle endurance was measured using push-ups and sit-ups. To evaluate muscle power and endurance of the subjects, ratings of interpretation (poor, fair, average, good, and excellent) were used to classify them according to the standard of physical fitness for Thai adolescents aged 7-18 years (Samahito, 2012).

\section{Self-esteem}

Self-esteem was assessed using the Thai Five-Scale Test of Self-Esteem for Children (FSC). The FSC consisted of five areas and 36 items: seven academic items, five body image items, nine family items, seven social items, and eight global items (Putthisri \& Silpakit, 1998).

\section{Ethical approval and permission}

This study, including the protocol and consent forms for students and their parents, was approved by the Ethics Committee at the Faculty of Medicine, Ramathibodi Hospital, University of Mahidol. Written informed consent was obtained from students and their legal guardians.

\section{Ethical clearance}

The study was approved by the Ethical Clearance Committee on Human Rights Related to Research Involving Human Subjects, Faculty of Medicine, Ramathibodi Hospital, Mahidol University (ID11-58-23).

\section{Statistical analysis}

Statistical analysis was performed using SPSS statistics version 15.0. General data, economic and social data, and nutritional status (anthropometric, 
biochemical, and dietary data) were presented as mean ( \pm standard deviation, $\mathrm{SD})$ or percentage. The differences in body composition, biochemical data, dietary data, physical fitness scores, and self-esteem scores were determined by repeated measures ANOVA. $P$-values $<0.05$ were considered as statistically significant.

\section{RESULTS}

Total energy intake during the BL period had a range of $1135-1493 \mathrm{kcal} /$ day and was $72.6-88.8 \%$ of the energy requirement (Table 1). In the HP period, the average total energy intake was $107.4 \%$ of the energy requirement. The last period was the HP-E period, and the average total energy intake was close to the energy requirement (94.9\%). However, energy intake in the HP-E period was not significantly different from that in the HP period.

In the BL period, protein intake of all subjects ranged from $1.7-2.1 \mathrm{~g} / \mathrm{kg} / \mathrm{d}$, which was higher than the Thai RDA (1.2 $\mathrm{g} / \mathrm{kg} / \mathrm{d}$ ) (Bureau of Nutrition, 2020). In addition, $70.3-84.4 \%$ of the total protein intake was derived from animal protein. The mean estimated total BCAA intake (isoleucine, leucine, and valine) was $13.78 \mathrm{~g} / \mathrm{d}(18.3 \%$ of total protein). In the HP period, mean protein intake was $2.34 \pm 0.14 \mathrm{~g} / \mathrm{kg} / \mathrm{d}$, ranging from 2.23$2.45 \mathrm{~g} / \mathrm{kg} / \mathrm{d}$, which was higher than the International Olympic Committee (IOC) and American College of Sports Medicine (ACSM) recommendations for strength and endurance athletes. The average protein intake in the HP-E period was $2.14 \pm 0.15 \mathrm{~g} / \mathrm{kg} / \mathrm{d}$, which was lower than that in the HP period $(2.34 \mathrm{~g} / \mathrm{kg} / \mathrm{d})$. The average protein and animal protein intake in the HP and HP-E periods were significantly different from that in the BL period. However, no significant difference in animal protein intake or percentage of BCAA intake was observed between the HP and HP-E periods (Table 1).

Tables 2 shows the body composition of subjects in each period. In the HP and HP-E periods, LTM and muscle

Table 1. Mean \pm SD of energy intake, energy distribution, and protein and total BCAA intakes of subjects during BL, HP and HP-E periods

\begin{tabular}{lccc}
\hline Parameters & BL period $(n=9)$ & HP period $(n=9)$ & HP-E period $(n=9)$ \\
\hline Energy requirement, kcal & $1591 \pm 67$ & $1655 \pm 74^{a}$ & $1913 \pm 90^{a b}$ \\
Energy intake, kcal & $1310 \pm 113$ & $1778 \pm 128^{a}$ & $1806 \pm 98^{a}$ \\
$\quad \%$ of energy requirement & $82.2 \pm 4.9$ & $107.4 \pm 6.7^{a}$ & $94.9 \pm 5.6^{a b}$ \\
Energy distribution, \% of total energy & & & \\
Carbohydrate & $49.9 \pm 2.6$ & $45.9 \pm 2.0^{a}$ & $49.5 \pm 1.5^{b}$ \\
Protein & $23.4 \pm 1.5$ & $22.7 \pm 1.2$ & $20.5 \pm 0.6^{a b}$ \\
Fat & $26.5 \pm 1.5$ & $31.3 \pm 1.2^{a}$ & $29.8 \pm 1.2^{a b}$ \\
Protein, g/d & $75.2 \pm 5.5$ & $99.6 \pm 5.5^{a}$ & $92.3 \pm 6.3^{a b}$ \\
g/kg/d & $1.8 \pm 0.1$ & $2.3 \pm 0.1^{a}$ & $2.1 \pm 0.1^{a b}$ \\
Animal protein, g/d & $58.8 \pm 5.3$ & $83.5 \pm 4.9^{a}$ & $73.4 \pm 5.9^{a}$ \\
$\quad \%$ of total protein & $78.2 \pm 4.0$ & $83.8 \pm 1.3$ & $79.4 \pm 0.9^{b}$ \\
Vegetable protein, g/d & $14.7 \pm 3.5$ & $15.1 \pm 1.3$ & $17.6 \pm 0.6^{b}$ \\
$\quad \%$ of total protein & $19.5 \pm 4.2$ & $15.2 \pm 1.1$ & $19.1 \pm 0.9^{b}$ \\
Total branched-chain amino acids, g/d & $13.7 \pm 1.0$ & $18.5 \pm 0.8^{a}$ & $17.2 \pm 1.2^{a b}$ \\
$\quad \%$ protein & $18.3 \pm 0.1$ & $18.6 \pm 0.2^{a}$ & $18.6 \pm 0.1^{a}$ \\
\hline
\end{tabular}

${ }^{a}$ Significant difference from the BL period: $p<0.05,{ }^{b}$ Significant difference from the HP period: $p<0.05$. 
Table 2. Mean $\pm \mathrm{SD}$ of height, body weight, BMI, body fat, lean tissue mass, muscle circumference, strength test results, and self-esteem scores among subjects during the different study periods

\begin{tabular}{|c|c|c|c|}
\hline Parameters & $B L$ period $(n=9)$ & HP period $(n=9)$ & $H P-E$ period $(n=9)$ \\
\hline Height, $\mathrm{cm}$ & $161.2 \pm 5.1$ & $164.0 \pm 4.8^{a}$ & $165.0 \pm 4.8^{a b}$ \\
\hline Weight, $k g$ & $40.1 \pm 2.3$ & $43.0 \pm 2.7^{a}$ & $43.5 \pm 2.9^{a}$ \\
\hline $\operatorname{BMI}\left(k g / m^{2}\right)$ & $15.4 \pm 0.2$ & $15.9 \pm 0.2^{a}$ & $15.9 \pm 0.3^{a}$ \\
\hline Body fat, $\%$ & $4.7 \pm 1.0$ & $6.0 \pm 0.8^{a}$ & $5.8 \pm 0.9^{a}$ \\
\hline LTM, $k g$ & $36.2 \pm 2.1$ & $38.3 \pm 2.4^{a}$ & $38.8 \pm 2.6^{a}$ \\
\hline Right arm, $\mathrm{kg}$ & $1.6 \pm 0.1$ & $1.7 \pm 0.1^{a}$ & $1.7 \pm 0.1^{a}$ \\
\hline Left arm, $\mathrm{kg}$ & $1.6 \pm 0.1$ & $1.7 \pm 0.1$ & $1.7 \pm 0.1^{a}$ \\
\hline Right leg, $\mathrm{kg}$ & $6.7 \pm 0.6$ & $7.0 \pm 0.8$ & $7.1 \pm 0.8^{a b}$ \\
\hline Left leg, $k g$ & $6.7 \pm 0.6$ & $6.9 \pm 0.8$ & $7.0 \pm 0.8$ \\
\hline Trunk, kg & $19.3 \pm 1.6$ & $20.8 \pm 1.4^{a}$ & $21.0 \pm 1.3^{a}$ \\
\hline \multicolumn{4}{|l|}{ Circumference, $\mathrm{cm}$} \\
\hline Upper arm & $19.1 \pm 0.6$ & $19.9 \pm 0.9^{a}$ & $20.2 \pm 1.1^{a}$ \\
\hline Forearm & $19.7 \pm 0.7$ & $20.1 \pm 1.3$ & $20.3 \pm 1.3^{a}$ \\
\hline Buttock & $78.6 \pm 3.1$ & $79.2 \pm 3.5$ & $79.3 \pm 3.4^{a}$ \\
\hline Mid-thigh & $38.2 \pm 1.4$ & $38.7 \pm 1.7$ & $38.9 \pm 1.7^{a}$ \\
\hline Calf & $29.9 \pm 1.3$ & $30.2 \pm 1.5$ & $30.5 \pm 1.5^{a}$ \\
\hline Waist & $60.1 \pm 2.6$ & $61.2 \pm 2.6^{a}$ & $61.2 \pm 2.6^{a}$ \\
\hline Abdomen & $62.0 \pm 2.5$ & $63.2 \pm 2.4^{a}$ & $63.3 \pm 2.5^{a}$ \\
\hline Hip & $67.2 \pm 3.3$ & $68.2 \pm 3.3^{a}$ & $68.2 \pm 3.3^{a}$ \\
\hline \multicolumn{4}{|l|}{ Strength tests } \\
\hline Push-ups (30 sec) & $14.6 \pm 3.3^{2}$ & $16.3 \pm 5.2^{a 2}$ & $19.6 \pm 5.0^{a b 2}$ \\
\hline Sit-ups (60 sec) & $34.6 \pm 8.0^{3}$ & $38.4 \pm 6.2^{a 4}$ & $44.0 \pm 4.9^{a b 4}$ \\
\hline Broad jump (cm) & $182.4 \pm 25.2^{4}$ & $191.2 \pm 25.0^{a 4}$ & $205.0 \pm 21.6^{a b 4}$ \\
\hline \multicolumn{4}{|l|}{ Self-esteem score } \\
\hline Academics & $9.4 \pm 1.6$ & $9.7 \pm 1.0$ & $10.0 \pm 1.8$ \\
\hline Body image & $6.5 \pm 2.1$ & $6.6 \pm 1.7$ & $7.6 \pm 1.7^{a b}$ \\
\hline Family & $14.7 \pm 1.9$ & $14.5 \pm 2.4$ & $15.1 \pm 2.5$ \\
\hline Global & $10.8 \pm 1.6$ & $11.3 \pm 2.3$ & $12.2 \pm 2.1$ \\
\hline Social & $10.1 \pm 2.0$ & $9.8 \pm 2.3$ & $10.3 \pm 3.7$ \\
\hline
\end{tabular}

${ }^{a}$ Significant difference from the BL period: $p<0.05$

${ }^{b}$ Significant difference from the HP period: $p<0.05$

BMI: body mass index, LTM: lean tissue mass

The meaning of the symbol for Strength tests: ${ }^{1}$ poor, ${ }^{2}$ fair, ${ }^{3}$ average, ${ }^{4}$ good, and ${ }^{5}$ excellent

circumferences (upper arm, waist, abdomen, and hip) were significantly higher than those in the BL period. Muscle strength (measured by pushups and sit-ups) and muscle power (measured by broad jump) were significantly improved in both HP and HP-E periods compared to BL period. The highest muscle strength and power levels were observed in the HP-E period $(p<0.05)$ (Table 2$)$. In addition, mean selfesteem score for body image in the HP-E period was statistically, significantly higher than in the HP period. However, no significant differences were observed in the self-esteem scores for academics, family, global, and social among the BL, HP, and HP-E periods (Table 2). 
Table 3. Mean $\pm \mathrm{SD}$ of body weight, lean tissue mass, and muscle circumference change normal growth rate, $\%$ per 8 weeks

\begin{tabular}{lcc}
\hline Parameters & HP period $(n=9)$ & HP-E period $(n=9)$ \\
\hline Normal weight status, $n$ & 4 & 4 \\
Body weight change - normal growth rate & 1.06 & 0.88 \\
LTM change - normal growth rate & 0.56 & 0.56 \\
Trunk LTM change - normal growth rate & 1.70 & 1.44 \\
Upper arm (MC change - normal growth rate) & 0.15 & 0.23 \\
Calf (MC change - normal growth rate) & 0.28 & 0.44 \\
Waist (MC change - normal growth rate) & 0.52 & 0.41 \\
Abdomen (MC change - normal growth rate) & 0.26 & 0.17 \\
Hip (MC change - normal growth rate) & 0.33 & 0.23 \\
\hline
\end{tabular}

LTM: lean tissue mass, MC: muscle circumference

After the HP and HP-E periods, subjects had weight gain at a normal growth rate of $1.06 \%$ and $0.88 \%$ per 8 weeks, respectively, and four out of nine underweight subjects had a normal weight status in the HP and HP-E periods (Table 3).

Table 4 shows the biochemical parameters including haemoglobin, FBS, TC, HDL-C, LDL-C, triglyceride (TG), serum uric acid, BUN, and creatinine in each period. All subjects' biochemical parameters were within the normal range during the BL, HP, and HP-E periods.
In the HP and HP-E periods, HDL-C and HDL-C/TC ratio were significantly higher than those in the $\mathrm{BL}$ period. In the HP-E period, HDL-C and HDL-C/TC ratio, and TG were significantly different from those in the HP period.

\section{DISCUSSION}

Underweight young men looking to increase muscle and body mass may rely on commercial whey proteins where their purity and safety may not be guaranteed. Aside from that, whey protein may cause

Table 4. Mean \pm SD of blood biochemical parameters of subjects during the different study periods

\begin{tabular}{lccc}
\hline Parameters & BL period $(n=9)$ & HP period $(n=9)$ & HP-E period $(n=9)$ \\
\hline Haemoglobin, g/dL & $14.4 \pm 1.7$ & $14.2 \pm 1.4$ & $14.3 \pm 1.1$ \\
FBS, mg/dL & $86.6 \pm 5.7$ & $85.5 \pm 5.0$ & $83.1 \pm 4.0$ \\
TC, mg/dL & $154.7 \pm 28.1$ & $161.0 \pm 25.7$ & $149.5 \pm 28.7$ \\
HDL-C, mg/dL & $57.4 \pm 13.9$ & $62.5 \pm 14.7^{a}$ & $49.5 \pm 13.4^{a b}$ \\
LDL-C, mg/dL & $86.4 \pm 21.9$ & $87.8 \pm 19.8$ & $87.1 \pm 22.4$ \\
LDL-C/HDL-C ratio & $1.51 \pm 11.8$ & $1.40 \pm 12.6^{a}$ & $1.76 \pm 14.71^{a b}$ \\
TG, mg/dL & $55.3 \pm 16.0$ & $53.2 \pm 13.1$ & $64.8 \pm 10.5^{b}$ \\
Serum uric acid, mg/dL & $5.8 \pm 0.8$ & $5.7 \pm 0.5$ & $5.4 \pm 0.7$ \\
BUN, mg/dL & $11.5 \pm 2.5$ & $11.2 \pm 3.0$ & $11.0 \pm 2.2$ \\
Creatinine, mg/dL & $0.69 \pm 0.09$ & $0.72 \pm 0.09$ & $0.70 \pm 0.08$ \\
\hline
\end{tabular}

${ }^{a}$ Significant difference from the BL period: $p<0.05$

${ }^{b}$ Significant difference from the HP period: $p<0.05$

FBS: fasting blood sugar, TC: total cholesterol, HDL-C: high density lipoprotein cholesterol, LDL-C: low density lipoprotein cholesterol 
some adverse effects such as delivering a marked acid load to the kidneys, increasing the risk for stone formation, decreasing estimated calcium balance, and possibly increasing the risk for bone loss (Reddy et al., 2002). Thus, caution should be exercised when using whey protein as a protein supplement. High protein diets combined with resistance training exercise may be a safer option for improving body weight and muscle mass.

In the BL period, total energy intake was $72.6-88.8 \%$ of the energy requirement, which may have caused all subjects to be underweight. Protein quality was assessed by protein, animal protein, and BCAA intakes. The mean protein intake of all subjects was 1.87 $\mathrm{g} / \mathrm{kg} / \mathrm{d}$, which was higher than the Thai RDA $(1.2 \mathrm{~g} / \mathrm{kg} / \mathrm{d})$ (Bureau of Nutrition, 2020) and consistent with a study on adolescents in Baham, Cameroon (Kenmogne-Domguia, Ponka \& Fokou, 2016). The study in Baham showed that protein intake of all subjects was significantly higher than their needs, while energy intake was significantly lower than their needs $(p<0.05)$. The high prevalences of stunted growth and wasting in males are related to the relatively low energy intake, which could divert amino acids for energy production.

In the HP period, subjects received energy and protein intakes of 1778 $\mathrm{kcal} / \mathrm{d}(107.4 \%$ of energy requirement) and $2.30 \mathrm{~g} / \mathrm{kg} / \mathrm{d}$, respectively; the extra energy and protein intakes came from their own snacks, which subjects were allowed to eat ad libitum in addition to their main meals. Pereira et al. (2013) suggested that children have been gradually putting on weight due to a small but persistent daily positive energy gap, from 70 to $160 \mathrm{kcal}$ above that is necessary for the growth process. This was consistent with the total energy intake in the HP period, which was higher than the energy requirement by $123 \mathrm{kcal}$. High protein intake in the HP period, which was more than that in the BL period by approximately $25.1 \%$, increased body weight and LTM by $1.06 \%$ and $0.56 \%$, respectively, when compared with the normal growth rate in the BL period (Table 3).

In the HP-E period, subjects had a total energy intake higher than that in the HP period because of their energy expenses for resistance exercise. The importance of maintaining energy balance is to preserve healthy body weight while increasing LTM. Negative energy balance generally results in muscle mass loss, the extent of which corresponds to the degree and duration of the deficit incurred (Murphy et al., 2018). In the HP-E period, protein intake was not different from that in the HP period, $2.14 \mathrm{~g} / \mathrm{kg} / \mathrm{d}$, which was $144.38 \%$ higher than that recommended by the Thai RDA (Table 1). In the HP-E period, resistance training exercise combined with a high protein intake $(2.14 \mathrm{~g} / \mathrm{kg} / \mathrm{d})$ increased body weight and LTM by $0.5 \mathrm{~kg}$ and $0.5 \mathrm{~kg}$, respectively. The important role of amino acid availability in regulating muscle protein synthesis (MPS) in response to amino acids, protein ingestion, and exercise has been reported (Glass, 2010). In addition, exercise enhanced the ability of skeletal muscle to respond to amino acid provision. The most likely contributing mechanism is an exercise-induced increase in blood flow to the muscle that increases the delivery of amino acids to the muscle, thus increasing the provision of substrate for MPS (Glass, 2010).

In addition, resistance training for eight weeks in the HP-E period increased arm, leg, and trunk muscle strength by $20.2 \%, 7.2 \%$, and $14.5 \%$, respectively, more than a high protein diet alone during the HP period. Faigenbaum et al. (2007) studied the effect of a nine-week 
resistance training on 22 middle school students aged 13.9 years. Their study indicated that subjects significantly improved arm muscle strength (bench press) by $15.0 \%$ and leg muscle strength (vertical jump) by $5.0 \%$, which were close to the results of our study. In the HP-E period, calf and mid-thigh circumferences increased by $0.12 \%$ and $0.06 \%$ per week, respectively, from the HP period. Our findings are consistent with those of Piazza et al. (2014), who studied the effect of resistance training in young athletes aged $11.9 \pm 1.0$ years and found that after six weeks of resistance training, calf and mid-thigh circumferences increased by $0.11 \%$ and $1.30 \%$ per week, respectively, from baseline.

After subjects had resistance training in the HP-E period, muscle strength and muscle power significantly improved when compared to HP period. However, no significant difference in LTM was observed between the HP and HP-E periods (Table 2). Our findings are consistent with the findings of Ormsbee et al. (2011) that resistance training enhanced muscle protein synthesis and increased muscle strength and hypertrophy. Protein and amino acid supplements have been shown to augment physiological improvements associated with resistance training, such as increasing body composition, muscular strength, and hypertrophy, while suppressing exercise-induced proteolysis. However, increasing strength and power after resistance training in both pre-adolescents and adolescents are usually attributed to increased neuromuscular activation and coordination, rather than muscle hypertrophy (Harries, Lubans \& Callister, 2012). A review of physiological adaptations following resistance training in youth athletes revealed adaptive processes in the neural system (Legerlotz et al., 2016). It is well documented that both neural and morphological factors contribute to increased muscle strength, as well as improved contraction characteristics in healthy adults, particularly in the early stage of training onset (Carroll et al., 2011). Regarding the effects of training in children, there seems to be general agreement that such neural adaptation appears to be the predominant mechanism responsible for exercise-induced strength, rather than muscle morphological changes (Behm et al., 2008).

In the HP and HP-E periods, subjects received a high protein diet. To assess safety, we evaluated biochemical parameters, including BUN and creatinine. There have been no reports of protein-induced diminutions in renal function despite subject populations that are generally at risk for kidney disease (Martin, Armstrong \& Rodriguez, 2005). Antonio et al. (2015) studied the effect of eight weeks of resistance training exercise combined with high protein intake from whey or beef protein powder in 17 healthy males and females, with an average age of 24.8 years. Subjects in the normal protein group and high protein group consumed $2.3 \mathrm{~g} / \mathrm{kg} / \mathrm{d}$ and 3.4 $\mathrm{g} / \mathrm{kg} / \mathrm{d}$ of dietary protein, respectively, during the intervention period. They found that BUN and creatinine levels were not significantly different between the normal protein group and the high protein diet group. Our study found that a high protein intake of $2.3 \mathrm{~g} / \mathrm{kg} / \mathrm{d}$ and $2.1 \mathrm{~g} / \mathrm{kg} / \mathrm{d}$ in the HP and HP-E periods, respectively, did not affect BUN and creatinine levels, which were within normal limits throughout the study.

LDL-C concentration has been the prime index of cardiovascular disease risk and the main target for therapy. However, a previous study suggested that TC/HDL-C and LDL/HDL cholesterol ratios are risk indicators with greater 
predictive value than isolated parameters used independently, particularly the former (Millán et al., 2009). TC/HDL-C ratio should be less than 4.5 and 4.0 in men and women, respectively. LDL/HDL cholesterol ratio should be less than 3.0 and 2.5 in men and women, respectively (Gotto AM et al., 2003). A recommended ratio is not available for adolescents yet. However, if we applied this ratio to the subjects, we found that all subjects had TC/HDL-C and LDL/HDL cholesterol ratios of lesser than 4.5 and 3.0, respectively, throughout the study. This study found significant increase in TG in the HP-E period. Consistent to Patel et al. (2015)'s study, they found that TG increased $13.6 \mathrm{mg} / \mathrm{dl}$ after eight weeks of resistance training intervention. The increased TG could be resulted from a greater need for fuel delivery, including a greater reliance on oxidative fuels such as fat, during resistance training, although this requires confirmation (Patel et al., 2015). However, TG levels of all subjects in our study remained within normal levels.

The present study of eight weeks resistance training on lipid profile in underweight adolescent males showed that resistance training may increase TG, decrease HDL-C, and tended to decrease TC and LDL-C, but there were no statistically significant differences. Our findings were similar with the results of lipid profile in overweight males on eight weeks resistance training, which found that resistance training tended to increase TG, decrease TC, LDL-C, and HDL-C, but there were no statistically significant differences (Patel et al., 2015).

In the HP-E period, mean self-esteem score for body image was significantly higher than in the HP period. The selfesteem score for body image was in parallel with improvements in body weight and muscle mass change, which is consistent with the finding of Velez, Golem \& Arent's (2010). They found that 12 weeks of resistance training exercise in adolescents yielded an increase in self-esteem scores for body image from pre-test to post-test, whereas no change was observed in the control group.

\section{STRENGTHS AND LIMITATIONS}

The strengths of the study were that the energy and protein intakes during each meal were calculated by the researchers and related to the subjects' activities, and that the food was prepared by the school cafeteria. Besides that, participants' compliance with dietary intake was $100 \%$ throughout the study. The weakness of this study was the short-term period of the study, which may have led to the non-significant difference of LTM change in the HP-E period when compared to the HP period. Therefore, the study duration should be at least 16 weeks for future studies.

\section{CONCLUSION}

Eight weeks of resistance training with upper-body and lower-body exercises combined with a high protein diet $(2.14$ $\mathrm{g} / \mathrm{kg} / \mathrm{d}$ ) increased body weight and LTM by $0.5 \mathrm{~kg}$ and $0.5 \mathrm{~kg}$, respectively. In addition, resistance exercise predominantly increased muscle strength and power, rather than muscle hypertrophy. The high protein intake did not affect kidney function throughout the study.

\section{Acknowledgements}

The authors would like to acknowledge all staffs of the PCSHSCR for their cooperation and assistance throughout this research. Enormous appreciation is extended to the participating school children for their good participation, cooperation, and friendliness. Funding for this research was partially provided by the Graduate Studies Program of the Mahidol University Alumni Association. 


\section{Authors' contributions}

WS, principal investigator, conceptualised and designed the study, prepared the draft of the manuscript and reviewed the manuscript; PL, conducted the study, data analysis and interpretation, assisted in drafting of the manuscript, reviewed the manuscript; SP and NT, assisted in drafting of the manuscript, reviewed the manuscript.

\section{Conflicts of interest}

None

\section{References}

Antonio J, Ellerbroek A, Silver T, Orris S, Scheiner M \& Gonzalez A (2015). A high protein diet $(3.4 \mathrm{~g} / \mathrm{kg} / \mathrm{d})$ combined with a heavy resistance training program improves body composition in healthy trained men and women - a followup investigation. J Int Soc Sports Nutr 12:39. doi:10.1186/s12970-015-0100-0.

Behm DG, Faigenbaum AD, Falk B \& Klentrou $P$ (2008). Canadian Society for Exercise Physiology position paper: resistance training in children and adolescents. Appl Physiol Nutr Metab 33(3):547-561. doi: 10.1139/H08-020.

Berrazaga I, Micard V, Gueugneau M \& Walrand $\mathrm{S}$ (2019). The role of the anabolic properties of plant- versus animal-based protein sources in supporting muscle mass maintenance: A critical review. Nutrients 11(8):1825. doi:10.3390/nu11081825.

Bray GA, Smith SR, Jonge Ld, Xie H, Rood J \& Martin CK (2012). Effect of dietary protein content on weight gain, energy expenditure, and body composition during overeating: a randomized controlled trial. JAMA 307(1):4755. doi: 10.1001/jama.2011.1918.

Bureau of Nutrition (2020). Dietary Reference Intake for Thais 2020 (PP 118). Ministry of Public Health, AV Progressive LP, Bangkok.

Carroll TJ, Selvanayagam VS, Riek S \& Semmler JG (2011). Neural adaptations to strength training: Moving beyond transcranial magnetic stimulation and reflex studies. Acta Physiol 202(2):119-140. doi: 10.1111/j.17481716.2011.02271.x.

De Onis M, Onyango WA \& Borghi E (2007). Development of a WHO growth reference for school-aged children and adolescents. Bulletin of the World Health Organization 85:660-667. doi: $10.2471 /$ blt.07.043497.
Donges CE, Duffield R \& Drinkwater EJ (2010). Effects of resistance or aerobic exercise training on interleukin-6, C-reactive protein, and body composition. Med Sci Sports Exerc 42:304-313. doi: 10.1249/ MSS.0b013e3181b117ca.

Faigenbaum AD, McFarland JE, Johnson L, Kang J, Bloom J \& Ratamess NA (2007). Preliminary evaluation of an after school resistance training program for improving physical fitness in middle school-age boys. Percept Mot Skills 104:407-415. doi:10.2466/pms.104.2.407415.

Glass DJ (2010). Signaling pathways perturbing muscle mass. Curr Opin Clin Nutr Metab Care 13: 225-229. doi: 10.1097/ mco.0b013e32833862df.

Gotto AM, Assmann G \& Carmena R (2000). The ILIB lipid handbook for clinical practice: blood lipids and coronary heart disease. 2nd ed. New York, NY: International Lipid Information Bureau.

Hammami R, Granacher U, Makhlouf I, Behm DG $\&$ Chaouachi A (2016). Sequencing effects of balance and plyometric training on physical performance in youth soccer athletes. JStrength Cond Res 30(12):3278-3289. doi: 10.1519/ JSC.0000000000001425.

Harries SK, Lubans DR \& Callister R (2012). Resistance training to improve power and sports performance in adolescent athletes: A systematic review and meta-analysis. $J$ Sci Med Sport 15: 532-540. doi: 10.1016/j. jsams.2012.02.005.

Inokuchi M, Matsuo N, Takayama JI \& Hasegawa $\mathrm{T}$ (2007). Prevalence and trends of underweight and BMI distribution changes in Japanese teenagers based on the 2001 National Survey data. Ann Human Biol 34(3):354-361. doi: 10.1080/03014460701300109.

Kenmogne-Domguia BH, Ponka $\mathrm{R} \&$ Fokou E (2016). Protein-Energy Intakes and Nutritional Status of in-School Adolescents in Baham, Cameroon. J Nutr Disorders Ther 6:2. doi: 10.4172/2161-0509.1000186

Kye S, Kwon SO, Lee SY, Lee J, Kim BH, Suh HJ \& Moonf HJ (2014). Under-reporting of energy intake from 24-hour dietary recalls in the Korean National Health and Nutrition Examination Survey. Osong Public Health Res Perspect 5(2):85-91. doi:10.1016/j. phrp.2014.02.002. 
Legerlotz K, Marzilger R, Bohm S \& Arampatzis A (2016). physiological adaptations following resistance training in youth athletes-a narrative review. Pediatr Exerc Sci 28:501-520. doi: $10.1123 /$ pes.2016-0023.

Martin WF, Armstrong LE \& Rodriguez NR (2005). Dietary protein intake and renal function. Nutr Metab 2:25. doi: 10.1186/1743-7075-225.

McCarthy HD, Cole TJ, Fry T, Jebb SA \& Prentice AM (2006). Body fat reference curves for children. Int $J$ Obes (Lond) 30(4):598-602. doi: $10.1038 /$ sj.ijo.0803232.

Millán J, Pintó X, Muñoz A, Zúñiga M, Rubiés-Prat J, Pallardo L, Masana L, Mangas A, HernándezMijares A, González-Santos P, Ascaso J \& PedroBotet J (2009). Lipoprotein ratios: Physiological significance and clinical usefulness in cardiovascular prevention. Vasc Health Risk Manag 5: 757-765.

Murphy NE, Carrigan CT, Karl JP, Pasiakos SM \& Margolis LM (2018). Threshold of Energy Deficit and Lower-Body Performance Declines in Military Personnel: A Meta-Regression. Sports Med. (Auckland, N.Z.) 48, 2169-2178.

Ormsbee MJ, Thomas D, Mandler WK, Kinsey AW, Riley CJ \& Panton LB (2011). Effects of pre- and post-exercise intake of performance supplements on body composition, circumferences, and muscle strength in trained men during 6 weeks of resistance training. $J$ the Int Soc Sports Nutr 8:1-2. DOI:10.1186/15502783-8-S1-P23.

Patel SJ, Hanks LJ, Ashraf AP, Gutierrez OM, Bamman MM \& Casazza K (2015). Effects of 8 weeks resistance training on lipid profile and insulin levels in overweight/obese peri- pubertal boys- a pilot study. Journal of Diabetes Research \& Clinical Metabolism 4. doi: 10.7243/2050-0866-4-2.
Pereira HRC, Bobbio TG, Antonio MAR \& Barros Filho ADA (2013). Childhood and adolescent obesity: how many extra calories are responsible for excess of weight. Rev Paul Pediatr 31(2):252-257. doi:10.1590/s010305822013000200018 .

Piazza M, Battaglia C, Fiorilli G, Innocenti G, Iuliano E \& Aquino G (2014). Effects of resistance training on jumping performance in preadolescent rhythmic gymnasts: a randomized controlled study. Ital J Anat Embryol 119(1):1019. DOI:10.13128/IJAE-14635.

Putthisri S \& Silpakit C (1998). The reliability and validity of Thai version of Five-Scale Test of Self-Esteem for Children. J Psychiatr Assoc Thailand 43(4):358-367.

Reddy ST, Wang CY, Sakhaee K, Brinkley L \& Pak CY (2002). Effect of low- carbohydrate highprotein diets on acid base balance, stoneforming propensity, and calcium metabolism. American Journal of Kidney Diseases 40: 265274. doi: 10.1053/ajkd.2002.34504.

Samahito S (2012). Construction of health-related physical fitness tests and norms for Thai children of age 7-18 Years: The Department of Physical Education. Sapachanya printing, Bangkok.

Suttikomin W, Leelahagul P, Khamvang S, Chaimongkol C \& Chaiwut N (2018). Obesity and serum uric acid in secondary schoolage students of srinagarindra the princess mother school, Phayao, Thailand. Indian $J$ Public Health 62(2):133-37. DOI: 10.4103/ijph. IJPH_117_17.

Velez A, Golem DL \& Arent SM (2010). The impact of a 12-week resistance training program on strength, body composition, and selfconcept of Hispanic adolescents. $J$ Strength Cond Res 24:1065-73. DOI: 10.1519/ JSC.0b013e3181cc230a. 